\title{
Reliability of Sexual Risk Behavior Interviews With Psychiatric Patients
}

\author{
Karen McKinnon, M.A., Francine Cournos, M.D., Heino F.L. Meyer-Bahlburg, Dr.rer.nat., \\ Jeannine R. Guido, M.A., Louis R. Caraballo, B.A., Elizabeth S. Margoshes, Ph.D., \\ Richard Herman, M.A., Rhoda S. Gruen, M.A., and Theresa M. Exner, Ph.D.
}

\begin{abstract}
Test-retest interviews examining recent sexual activity were administered to 27 severely ill psychiatric patients after stabilization. Three reports were judged to be questionable. For the 16 sexually active patients among the remaining 24 , high test-retest reliability was found for number of sexual partners, frequency of episodes, and proportions of episodes involving vaginal intercourse and use of condoms. The interviews did not exacerbate psychiatric symptoms.

(Am J Psychiatry 1993; 150:972-974)
\end{abstract}

I n a recent study (1), one $(5.6 \%)$ of 18 patients admitted to two public psychiatric hospitals in New York City was HIV positive. Among these patients, past use of injection drugs was associated with HIV infection (1), but unsafe sexual activity appears to be the most prevalent current risk factor for acquiring or transmitting HIV (2).

Identification of high-risk activities is essential to performing appropriate HIV counseling and to designing targeted prevention strategies (1). Whether people with severe mental illness can be interviewed about their sexual behavior reliably and without substantial exacerbation of psychiatric symptoms has been largely unaddressed in the psychiatric literature.

Data on the frequency and nature of sexual activity among the severely mentally ill are limited (3-8), and the association between psychiatric disorders and sexual activity remains unclear.

As part of a larger interview study investigating how psychiatric symptoms and HIV risk-taking behaviors are related, we conducted a pilot study 1) to learn whether psychiatric patients could tolerate a detailed sexual behavior interview and 2) to establish the reliability of sexual risk histories with severely mentally ill inpatient and outpatient groups.

Received Jan. 28, 1992; revision received Sept. 21, 1992; accepted Oct. 29, 1992. From the Washington Heights Community Service Research Office, the Research Foundation for Mental Hygiene, and the HIV Center for Behavioral and Clinical Studies, New York State Psychiatric Institute, and the Department of Psychiatry, College of Physicians and Surgeons, Columbia University, New York. Address reprint requests to Dr. Cournos, New York State Psychiatric Institute, Unit 112, 722 West 168th St., New York, NY 10032.

Funded by NIMH grant MH-46251 and the New York State Office of Mental Health.

The authors thank Ewald Horwath, M.D., and the staff and patients of the Washington Heights Community Service.

Copyright $(1) 1993$ American Psychiatric Association.

\section{METHOD}

Eligible patients were between the ages of 18 and 59 years, spoke English, and could give informed consent. Paid volunteers were recruited from a 22-bed acute care inpatient unit and a day treatment program serving 80 primarily chronically ill patients at a public psychiatric hospital in New York City. Eligible inpatients were referred by their treating psychiatrists. Day treatment patients responded to an announcement of the study at a community meeting or to notices posted in the lunch room. Thirty patients volunteered to participate in a test-retest interview study of sexual behaviors occurring in the past 6 months. Of these, three were excluded because they could not be reinterviewed within 60 days because of scheduling difficulties or transfer to another facility. The remaining 27 patients completed both interviews. Nonvolunteers were not evaluated.

The Sexual Risk Behavior Assessment Schedule (9) was administered. This interview, developed for injection drug users and adapted for a psychiatric population, elicits detailed oral reports of sexual behaviors in the past 6 months. The item order, exploration of patients' sexual vocabulary, and interviewers' explicit definitions of sexual practices are designed to put patients at ease when talking about sex. The 45-minute interview can be completed in multiple sessions.

The Sexual Risk Behavior Assessment Schedule contains an interviewer rating of the quality of the patient's reports that takes into account impairments in the patient's concentration and memory, interference of psychiatric symptoms in understanding and responding to questions, and degree of comfort with the topic. The interview was scored on a 4-point scale in which 1 indicates "high quality," 2 a "generally reliable" report, 3 a "questionable" report, and 4 an "unsatisfactory" report. The reasons for questionable or unsatisfactory reports are recorded.

One male and one female interviewer who were mental health professionals not involved in the direct care of the patients each received a minimum of 20 hours of seminar-style training and approximately 15 hours of interviewing practice. The training included desensitization to sexual terminology, an overview of human sexual response and dysfunction and potential adverse patient reactions, and instruction in the interview method. Audiotape recordings of practice interviews were reviewed by the interview supervisor. The study began only after the supervisor was confident of the interviewers' ability to use the instrument.

The interviewers and subjects were not matched on gender, race, or sexual orientation. To counter potential response sets by individual patients and to provide a component of interrater reliability, the interviewers were alternated so that one did not conduct both the 
BRIEF REPORTS

TABLE 1. Characteristics of 24 Psychiatric Patient Volunteers Reporting on Sexual Activity in the Past 6 Months

\begin{tabular}{|c|c|c|}
\hline Patient Characteristic & $\mathrm{N}$ & $\%$ \\
\hline \multicolumn{3}{|l|}{ Sexually active } \\
\hline Yes & 16 & 66.7 \\
\hline No & 8 & 33.3 \\
\hline \multicolumn{3}{|l|}{ Location at interview } \\
\hline Acute admissions unit & 4 & 16.7 \\
\hline Day program & 20 & 83.3 \\
\hline \multicolumn{3}{|l|}{ Ethnicity } \\
\hline White & 2 & 8.3 \\
\hline Hispanic & 12 & 50.0 \\
\hline Black & 10 & 41.7 \\
\hline \multicolumn{3}{|l|}{ Gender } \\
\hline Male & 16 & 66.7 \\
\hline Female & 8 & 33.3 \\
\hline \multicolumn{3}{|l|}{ Age (years) } \\
\hline $18-29$ & 3 & 12.5 \\
\hline $30-39$ & 12 & 50.0 \\
\hline $40-49$ & 4 & 16.7 \\
\hline $50-59$ & 5 & 20.8 \\
\hline \multicolumn{3}{|c|}{ Highest level of education completed } \\
\hline 8 th grade or less & 12 & 50.0 \\
\hline High school or GED & 11 & 45.8 \\
\hline College & 1 & 4.2 \\
\hline \multicolumn{3}{|l|}{ Marital status } \\
\hline Never married & 14 & 58.4 \\
\hline Married & 2 & 8.3 \\
\hline Separated or divorced & 8 & 33.3 \\
\hline \multicolumn{3}{|c|}{ Domicile before hospitalization } \\
\hline Own house or apartment & 21 & 87.5 \\
\hline Group home & 1 & 4.2 \\
\hline Shelter or street & 2 & 8.3 \\
\hline \multicolumn{3}{|c|}{ Number of previous psychiatric hospitalizations } \\
\hline 1 & 6 & 25.0 \\
\hline $2-10$ & 18 & 75.0 \\
\hline \multicolumn{3}{|c|}{ Substance abuse history (chart) } \\
\hline Yes & 17 & 70.8 \\
\hline No & 7 & 29.2 \\
\hline \multicolumn{3}{|c|}{ Most recent axis I diagnosis (chart) } \\
\hline Schizophrenia & 17 & 70.8 \\
\hline Bipolar disorder & 3 & 12.5 \\
\hline Schizoaffective disorder & 3 & 12.5 \\
\hline Organic brain syndrome & 1 & 4.2 \\
\hline
\end{tabular}

initial and retest interviews with the same patient. The mean interval between the two interviews was 33.71 days $(S D=28.00)$.

The interview supervisor reviewed the interviewer ratings of the patient reports and audiotape recordings of all interviews. Ratings judged by both interviewer and supervisor as questionable or unsatisfactory were excluded from analysis.

For common HIV risk-related behaviors we calculated correlation coefficients for the relationship between interview and reinterview; kappas were determined for categorical variables, and Pearson $r$ and intraclass correlations were used for rank-transformed variables (10).

\section{RESULTS}

The patients appeared to respond well to the interviews. In fact, many patients reported being pleased to be asked about a normal aspect of life. There were no patient reports of distress or staff complaints about deleterious effects, and no interview needed to be prematurely terminated. Of the 27 patient volunteers who completed the test and retest interviews, three (11\%) were judged to have provided questionable reports be-
TABLE 2. Test-Retest Reliability Coefficients for Psychiatric Patient Volunteers Reporting on Sexual Activity in the Past 6 Months

\begin{tabular}{|c|c|c|c|c|}
\hline Variable & $\mathbf{N}$ & $\mathbf{r}$ & $\begin{array}{c}\text { Intraclass } \\
\text { Correlation } \\
\text { Coefficient } \\
\end{array}$ & Kappa ${ }^{a}$ \\
\hline $\begin{array}{l}\text { Sexually active (yes/no) } \\
\text { Number of sexual partners } \\
\text { Number of sexual episodes } \\
\text { Proportion of episodes in } \\
\text { which vaginal intercourse } \\
\text { occurred } \\
\text { Proportion of vaginal inter- } \\
\text { course episodes in which } \\
\text { condoms were used }\end{array}$ & $\begin{array}{l}24 \\
16 \\
16\end{array}$ & $\begin{array}{l}0.74^{b} \\
0.88^{b} \\
0.60^{c}\end{array}$ & $\begin{array}{l}0.76 \\
0.88\end{array}$ & 0.82 \\
\hline
\end{tabular}

cause of cognitive deficits (memory impairment associated with polydrug abuse, inability to concentrate). Of the remaining 24 patients, 16 reported sexual activity during the previous 6 months. Eight patients reported no sexual activity during the previous 6 months at both the interview and reinterview. Reliability coefficients were calculated for HIV-related heterosexual variables: sexually active (dichotomized yes/no), number of sexual partners and number of episodes, proportion of episodes in which vaginal intercourse occurred, and proportion of vaginal intercourse episodes in which condoms were used. No patient reported homosexual activity or anal intercourse.

Characteristics of the 24 patients reporting on heterosexual activity in the past 6 months are shown in table 1 . The subjects were demographically and clinically representative of the patient populations at both the inpatient and day treatment units. Most were diagnosed with schizophrenia and had had two or more prior psychiatric hospitalizations.

The test-retest reliability coefficients for risk-related behaviors occurring in the past 6 months are shown in table 2 and ranged between 0.61 and 0.89 .

\section{DISCUSSION}

No exacerbation of psychiatric symptoms was observed in response to explicit sexual interviews. Cognitive deficits interfered with patient reports for only three $(11 \%)$ of the 27 patients. Most of these patient volunteers at a public psychiatric hospital were able to reliably report specific sexual behaviors for the previous 6 months. Reports of number of sexual partners, number of sexual episodes, and proportions of episodes in which vaginal intercourse occurred and condoms were used were consistent after an average interval of 4 weeks.

Our patients reported no homosexual activity or anal intercourse during the preceding 6 months. This is unlikely to be a reporting artifact given that studies using similar versions of the Sexual Risk Behavior Assessment 
Schedule and identical interviewer training have yielded comparable prevalence rates of both behaviors for predominately black and Hispanic groups consisting of runaway youths (12) and severely mentally ill homeless men (Susser, unpublished data). We assume that the explanation lies in the relatively modest size of our study group, which by chance did not include patients practicing either sexual activity during the reporting period.

This study combines in its design an examination of test-retest reliability and interrater reliability because different interviewers were used on the two occasions. Given the length of the retest interval, the practice of alternating interviewers, and the exclusion of consistently sexually inactive patients, the reliability coefficients obtained probably represent lower limits and, therefore, conservative estimates. This assumes that obviously poor reports are excluded.

Limitations to the generalizability of our findings include potential sampling bias since the study included only a small number of subjects, particularly inpatients, and all participants were paid volunteers, who may constitute a self-selected group of sexually less inhibited or psychiatrically more stable patients than nonvolunteers. Furthermore, the participants had been evaluated by clinicians as capable of giving informed consent, thereby excluding patients who were considered acutely ill and not yet stabilized. However, the participants did not appear to differ from the overall census of either unit, and in our larger interview study, in which all eligible patients on the same units were sampled, nearly $83 \%$ consented to participate and only a small proportion of reports $(6 \%)$ were judged to be of questionable or unsatisfactory quality (2).

This pilot study demonstrates that structured, sensitive probing of sexual risk histories by well-trained mental health professionals can be done with stabilized inpatients and outpatients and can yield reliable information essential to HIV risk reduction efforts. Patients with cognitive impairment (three in our group) might be successfully interviewed if their condition improves or with multiple interview sessions over time.

Although devised as a research instrument, the Sexual
Risk Behavior Assessment Schedule can serve in clinical settings as a model for taking sexual risk histories. It provides an approach to training appropriate clinical staff to elicit behaviorally specific information about sexual behaviors from patients. We urge clinicians to attempt decisive HIV risk detection efforts with severely mentally ill patients as the basis for HIV testing and counseling.

\section{REFERENCES}

1. Cournos F, Empfield M, Horwath E, McKinnon K, Meyer I, Schrage H, Currie C, Agosin B: HIV seroprevalence among patients admitted to two psychiatric hospitals. Am J Psychiatry 1991; 148:1225-1230

2. Cournos F, Empfield M, McKinnon K, Weinstock A, Horwath E, Meyer I, Currie C: HIV seroprevalence and risk behaviors among homeless and hospitalized mentally ill, in Abstracts, VII International Conference on AIDS. Rome, Istituto Superiore di Sanita, 1991

3. Holbrook T: Policing sexuality in a modern state hospital. Hosp Community Psychiatry 1989; 40:75-79

4. Binder RL: Sex between psychiatric inpatients. Psychiatr Q 1985; 57:121-126

5. Akhtar S, Crocker E, Docleu N, Helfrich J, Rheubau WJ: Overt sexual behavior among psychiatric inpatients. Dis Nerv Syst 1977; 38:359-361

6. Verhulst J, Schneidman B: Schizophrenia and sexual functioning. Hosp Community Psychiatry 1981; 32:259-262

7. Raboch J: Sexual development and life of psychiatric female patients. Arch Sex Behav 1986; 15:341-353

8. Kelly JA, Murphy DA, Bahr GR, Brasfield TL, Davis DR, Hauth AC, Morgan MG, Stevenson LY, Eilers MK: AIDS/HIV risk behavior among the chronic mentally ill. Am J Psychiatry 1992; 149:886-889

9. Meyer-Bahlburg HFL, Ehrhardt AA, Exner TM, Gruen RS: Sexual Risk Behavior Assessment Schedule-Adult-Psychiatric Inpatient Interview. New York, New York State Psychiatric Institute, June 6, 1990

10. Conover WJ, Iman RL: Rank transformations as a bridge between parametric and nonparametric statistics. Am Statistician 1981; 35(3):124-133

11. Fleiss JL: Statistical Methods for Rates and Proportions, 2nd ed. New York, John Wiley \& Sons, 1981, p 218

12. Rotheram-Borus MJ, Meyer-Bahlburg HFL, Koopman C, Rosario M, Exner TM, Henderson R, Matthieu M, Gruen RS: Lifetime sexual behaviors among runaway males and females. J Sex Res 1992; 29:15-29 